\title{
Editorial
}

\section{Educación superior dental: un reto para el docente universitario en tiempos de pandemia}

\author{
Dental education: a challenge \\ for university teachers in times of \\ pandemic
}

María Elena Inocente-Díaz ${ }^{1, a}$, María Elena Díaz-Pizán ${ }^{1,2, b}$

1 Universidad Peruana Cayetano Heredia, Facultad de Estomatología, Lima, Perú.

2 Universidad Nacional Mayor de San Marcos, Facultad de Odontología, Lima, Perú.

a Cirujano Dentista.

${ }^{\mathrm{b}}$ Doctora en Estomatología.

\section{Correspondencia:}

María Elena Inocente-Díaz: maria.inocente.d@upch.pe Av. Juan Pablo Fernandini 1584, Pueblo Libre, Lima, Perú. ORCID: 0000-0003-3536-7374

\section{Coautora:}

María Elena Díaz-Pizán: maria.diaz.p@upch.pe ORCID: 0000-0002-1615-5512

Recibido: 22/06/20

Aceptado: 25/06/20

Publicado: 04/08/20
Hace unos días, fuimos testigos de la viralización de un video en redes sociales, cuyo protagonista era Rolando Solis Navarro, un docente de la Facultad de Psicología de la Universidad Nacional Mayor de San Marcos. Dicho video fue grabado por su hija (sin que él se diera cuenta) en su primer día de clases virtuales y resumía toda la preparación previa y empeño que le había puesto para el dictado de su clase. Incluso, se pudo notar cierto nerviosismo en el profesor durante los minutos previos a la primera conexión con sus alumnos. Pero finalmente, enfrentó la situación y dictó su clase con éxito. Al igual que él, muchos docentes universitarios están poniendo su mayor esfuerzo y dedicación para adaptarse a este tipo de educación (virtual), a la que la pandemia actual, los ha forzado a enfrentarse bruscamente.

La historia ha sido testigo de muchas enfermedades, pero son pocas las referencias que se tienen de epidemias devastadoras que hayan afectado drásticamente el continuo funcionamiento de las universidades. Por ejemplo, en 1665 la "Gran Peste de Londres" causó el cierre (por 2 años) de la Universidad de Cambridge en el Reino Unido y, como consecuencia, los estudiantes tuvieron que volver a sus pueblos y hogares para estar en confinamiento, ya que "la enfermedad se propagaba por doquier" '. Sin embargo, nadie se imaginó en aquel entonces que ese largo confinamiento marcaría un antes y un después en el desarrollo de la Física y en la vida de Isaac Newton, un estudiante de Cambridge por aquellos años. Gracias a sus ratos de soledad y tiempo "libre", algo tan simple como la caída de una manzana, lo hizo reflexionar sobre la gravedad, sentando así las bases de lo que después se convertiría en su "Teoría de Gravitación Universal" 1.

De lo anterior, podemos rescatar que por más que surjan adversidades que nos alejen bruscamente de nuestros "cómodos" centros de formación o de labor docente, tenemos que continuar con el ejercicio del conocimiento y con nuestras actividades académicas 
donde nos encontremos ya que, "las actividades académicas continúan allí donde hay espíritus comprometidos con la ciencia y la formación" ${ }^{2}$ y no continúan meramente en las infraestructuras universitarias per se. Así, el confinamiento a causa de la COVID-19, puede ser también una oportunidad para conseguir resultados sorprendentes en la educación superior, saliendo beneficiados tanto docentes como alumnos ${ }^{3}$.

Pero, ¿por qué los docentes en vez de considerar esta situación como una oportunidad, la tomamos inicialmente como un reto difícil de enfrentar? Todo radica en el escaso acercamiento que hemos tenido con la educación virtual. En el Perú, hasta hace poco han sido contados los programas de educación superior que incluían clases virtuales o herramientas online. Si bien es cierto, que desde hace algún tiempo la mayoría de universidades, cuenta con una plataforma virtual, su uso era muy limitado. Teníamos un contacto superficial con estas plataformas y no las utilizábamos como herramientas constantes en la docencia. A esta realidad, se sumó una pandemia mundial altamente contagiosa que nos ha forzado al aislamiento social, siendo la educación virtual, la única vía que nos asegura la continuidad del proceso de enseñanza-aprendizaje en educación superior. Sin embargo, este abrupto paso de una educación presencial (sincrónica) a una educación online (sincrónica, asincrónica o mixta) con un sinfín de posibilidades por explorar, ha sido prácticamente un shock para nosotros con el que estamos tratando de lidiar ${ }^{4}$, poniendo a prueba nuestra capacidad de resiliencia. Incluso, para muchos profesores con vasta experiencia y largos años de docencia, cambiar de modelo de enseñanza va más allá, porque implica cambiar hábitos y rutinas diarias que ya estaban instauradas en sus formas de dictar clases.

Pero ¿qué implica enseñar de manera virtual?, ¿significa acaso dictar el mismo tipo de clase que solíamos realizar de manera presencial, pero frente a una computadora? En realidad, no. Enseñar presencialmente y enseñar virtualmente son dos cosas muy diferentes. Y la razón radica en que estas dos modalidades de enseñanza se desarrollan en escenarios distintos, tienen diferentes tipos de interacción y herramientas. Por ello, enseñar de manera virtual implica transformar (y no trasladar) lo que hacemos en entornos presenciales a entornos online ${ }^{4}$. Ruben Puentedura se refiere a esto como una "redefinición, mas no una réplica del modelo tradicional de enseñanza" 5. Es decir, el profesor acostumbrado a lo presencial "tendrá que reimaginar, reinventar sus metodologías y estrategias educativas, utilizando la tecnología más adecuada para que sus enseñanzas lleguen a buen término" " en un entorno virtual.

Los modelos de enseñanza, que desde hace algún tiempo, incluían elementos online son: el Flipped Learning y el Blended Learning. Ambos, llamados también modelos mixtos o semipresenciales porque cuentan con un escenario virtual y otro presencial, utilizándose cada uno de ellos, según los requerimientos del docente ${ }^{4}$.

Por otro lado, tenemos al E-Learning y los MOOC (del inglés Massive Online Open Courses o Cursos Abiertos
Masivos Online), modelos de enseñanza exclusivamente virtuales. En el primero, encontramos plataformas online establecidas con cursos empaquetados; mientras que los MOOC representan el modelo de enseñanza más tecnológico, en el que incluso ya no existe interacción entre el profesor y el alumno ${ }^{4}$. En los MOOC, es el alumno el único encargado de la distribución de sus horas de clase y de la velocidad con la que quiere llevar el curso. Sólo tiene que preocuparse por finalizar sus tareas y el trabajo final de la asignatura en una fecha determinada.

La pandemia actual, ha favorecido el surgimiento de un nuevo modelo de enseñanza, que representa el equilibrio de los grupos antes mencionados: semipresenciales y virtuales. Este nuevo modelo es una adaptación del Flipped Learning a un entorno virtual, que se conoce como "Flipped Learning Online". En ambos existe un espacio individual, donde el alumno trabaja solo y asincrónicamente; y un espacio grupal, donde el alumno trabaja sincrónicamente con el docente. La diferencia es que en el Flipped Learning, el espacio grupal se da en un entorno presencial, mientras que en el Flipped Learning Online, este espacio grupal se da virtualmente ${ }^{4}$.

En la Facultad de Odontología de la Universidad Nacional Mayor de San Marcos, se está empezando a utilizar justamente el modelo Flipped Learning Online, con clases divididas en espacios individuales asincrónicos, que se desarrollan en la plataforma Classroom; y en espacios grupales sincrónicos, que se ejecutan en la plataforma Meet.

En los espacios individuales virtuales de nuestros alumnos, podemos publicar material didáctico tal como: videos, lecturas, estudios de casos, podcasts, los cuales tienen que ser vistos, escuchados o leídos antes del inicio de las clases grupales. El objetivo es que los estudiantes estén preparados con antelación para los temas que se tratarán grupalmente. Así, las clases grupales virtuales, no servirán tanto para la transmisión de contenido, sino más bien serán tiempos de discusión, de debate, de feedback, de resolución de problemas y aplicación de soluciones ${ }^{6-8}$. El profesor, más que un "desarrollador" de contenido, tendrá la función de "coach" para los estudiantes ${ }^{7}$. Se ha demostrado también, que este modelo de enseñanza (Flipped Learning), mejora la adquisición del conocimiento en los alumnos y es el modelo más preferido por ellos ${ }^{6}$. Quizás la razón de esto es que al darles una actividad para que realicen previamente a la clase, despertamos su interés y motivación, se sienten más preparados en los temas y se animan a participar más. Es decir, disfrutan más de las clases. Y es que lo que limita la participación de los estudiantes, es su insuficiente preparación antes de clases ${ }^{8}$, tal como dice Raúl Santiago "uno no puede participar de lo que no sabe" ${ }^{4}$.

En la educación dental virtual, existen mayores desafíos. Pues, así como la medicina, la odontología es una carrera que requiere que el estudiante desarrolle competencias profesionales a través de la práctica ${ }^{2}$. En ese sentido, las plataformas virtuales serían "suficientes" para los 
alumnos de los años iniciales o preclínicos, pero "no del todo suficientes" para los estudiantes de años superiores, que requieren un ambiente clínico y un contacto directo con el paciente. Es justamente la comunicación y el examen constante de los pacientes, lo fundamental para el aprendizaje de estos estudiantes y para la formación de su pensamiento y criterio diagnóstico y clínico ${ }^{9}$. Como docentes de odontología, lo que podemos hacer para compensar de alguna manera esta falta de experiencia clínica, es incluir en nuestras clases virtuales (sobre todo en los espacios individuales de los alumnos) repositorios de casos clínicos con fotografías, entrevistas y grabaciones, para la posterior discusión de éstos en escenarios grupales online, tal como lo está haciendo la Facultad de Medicina del Imperial College London ${ }^{9}$. También se pueden incluir videos demostrativos sobre ciertos procedimientos clínicos o de laboratorio e imágenes de casos junto con cuestionarios sobre su diagnóstico o tratamiento, como lo esta haciendo la Escuela de Medicina de Harvard ${ }^{10}$.

Es cierto, que todo lo mencionado anteriormente, jamás podrá reemplazar la experiencia clínica directa con el paciente, pero este periodo nos servirá justamente como una oportunidad para potenciar las competencias teóricas y preclínicas de nuestros alumnos. Y de esta manera, cuando se retomen las actividades prácticas tanto en la clínica como en los laboratorios, tengamos alumnos más motivados y preparados en conocimientos para poner sus manos en acción.

Finalmente, nuestro compromiso como docentes debería ser mantenernos motivados en seguir aprendiendo nuevas herramientas online que enriquezcan nuestros métodos de enseñanza. Y el compromiso de las universidades, seguir capacitando a sus docentes no solo en educación virtual, sino también en pedagogía, porque un buen pedagogo podrá discernir la mejor metodología, las mejores estrategias y las mejores herramientas para llegar a sus alumnos, incluso en escenarios online. Además, es necesario el monitoreo y seguimiento de los docentes para evaluar la eficacia de sus competencias digitales en el tiempo.

\section{Referencias bibliográficas}

1. El Español. La cuarentena de Isaac Newton: el confinamiento que propició la teoría de la gravedad [Internet]. 12 Abril 2020 [citado el 27 de mayo del 2020]. Disponible en: https:/www.elespanol.com/cultura/historia/20200412/cuarentena-isaac-newton-confinamiento-propicio-teoria-gravedad/477952808_0.html

2. UNESCO. COVID-19 y educación superior: De los efectos inmediatos al día después [Internet]. 13 Mayo 2020 [citado el 28 de mayo del 2020]. Disponible en: http:// www.iesalc.unesco.org/wp-content/uploads/2020/05/ COVID-19-ES-130520.pdf

3. Anderson ML, Turbow S, Willgerodt MA, Ruhnke GW. Education in a Crisis: The Opportunity of Our Lives. J Hosp Med. 2020;15(5):287-291.

4. Novedades Académicas PUCP. El cambio de la enseñanza presencial a la remota [Video File]. Raúl Santiago (Universidad de la Rioja). 9 Junio 2020 [citado el 9 de junio del 2020] [1:17 min]. Disponible en: https://www.facebook.com/novedadesacademicaspucp/ videos/688303838619527

5. Puentedura R. SAMR: Moving from enhancement to transformation [Internet]. 29 Mayo 2013 [citado el 10 de Junio del 2020]. Disponible en: http://www.hippasus. com/rrpweblog/archives/2013/05/29/SAMREnhancementToTransformation.pdf

6. Chick R, Clifton G, Peace K, Propper B, Hale D, Alseidi A, Vreeland T. Using Technology to Maintain the Education of Residents During the COVID-19 Pandemic. J Surg Educ. 2020;77(4):729-732.

7. Lipomi DJ. Video for Active and Remote Learning. Trends in Chemistry. 2020;2(6):483-485.

8. Bao W. COVID-19 and online teaching in higher education: A case study of Peking University. Hum Behav \& Emerg Tech. 2020;2:113-115.

9. Mian A, Khan S. Medical education during pandemics: a UK perspective. BMC Med. 2020;18:100.

10. Almarzooq Z, Lopes M, Kochar A. Virtual Learning During the COVID-19 Pandemic: A Disruptive Technology in Graduate Medical Education. J Am Coll Cardiol. 2020;75(20):2635-2638. 
